\title{
Characterization of COPD Admissions During the First COVID-19 Outbreak
}

\author{
Borja G Cosio $\mathbb{D}^{1,2}$ \\ Hanaa Shafiek (iD) 1,3 \\ Nuria Toledo-Pons (iD) ${ }^{1,2}$ \\ Amanda Iglesias (D) 1,2 \\ Margalida Barcelo' \\ Cristina Represas-Represas ${ }^{4}$ \\ Lorena Comeche ${ }^{5}$ \\ Pablo Catalan ${ }^{6}$ \\ Alberto Fernandez-Villar ${ }^{4}$ \\ Jose Luis Lopez- Campos (iD ${ }^{7}$ \\ Jose Echave-Sustaeta ${ }^{5}$ \\ Juan Jose Soler-Cataluna ${ }^{8}$ \\ 'Respiratory Medicine, Hospital \\ Universitario Son Espases-IdISBa, Palma \\ de Mallorca, Spain; ${ }^{2}$ CIBERES-IDISBa, \\ Palma de Mallorca, Spain; ${ }^{3}$ Chest \\ Diseases Department, Faculty of \\ Medicine, Alexandria University, \\ Alexandria, Egypt; ${ }^{4}$ Respiratory Medicine, \\ Hospital Alvaro Cunqueiro, Vigo, Spain; \\ ${ }^{5}$ Respiratory Medicine, Hospital \\ Universitario Quironsalud Madrid, \\ Madrid, Spain; ${ }^{6}$ Respiratory Medicine, \\ Hospital General de Castellón, Castellón, \\ Spain; ${ }^{7}$ Respiratory Medicine, Hospital \\ Virgen del Rocio-CIBERES, Sevilla, Spain; \\ ${ }^{8}$ Respiratory medicine, Hospital Arnau de \\ Vilanova-CIBERES, Valencia, Spain
}

Correspondence: Borja G Cosio Hospital Universitario Son Espases, Ctra de Valldemossa 79, Palma de Mallorca, 07010 , Spain

Tel +34 87I 206714

Email borja.cosio@ssib.es

\begin{abstract}
Purpose: Exacerbations of COPD (ECOPD) are a frequent cause of hospitalization that seemed to ameliorate during the COVID outbreak. We aimed to evaluate the clinical characteristics of COPD-related hospital admissions and mortality in relation to the presence of COVID-19.

Patients and Methods: We conducted a case-control study of patients admitted in four teaching hospitals throughout Spain between March 15 and April 30, 2020. Hospital admissions of respiratory cause with and without PCR-proven SARS-CoV-2 infection in patients with COPD were evaluated. Baseline and episode-related clinical characteristics were analyzed. Logistic regression analysis was performed to evaluate the risk for mortality.

Results: During the study period, 2101 patients were admitted for respiratory worsening, $1200(57.1 \%)$ with COVID-19. A total of 228 (10.8\%) were admitted due to COPD worsening, of whom $52(22.8 \%)$ tested positive for COVID-19. COPD patients with COVID-19, when compared to those without COVID-19, were more frequently males with better lung function $\left(\mathrm{FEV}_{1}\right.$ postbronchodilator $71 \%$ vs $46 \%$ respectively, $\left.p<0.001\right)$ and had higher mortality ( $44.9 \%$ vs $13.6 \%$ respectively, $p<0.001$ ) despite similar age, comorbidities, total days of hospitalization and admission to intensive care unit. COVID-19 and eosinopenia were the strongest risk factors for mortality in the multivariate analysis in the overall COPD population. Inhaled corticosteroid use was not associated to mortality.

Conclusion: Hospitalizations for ECOPD without COVID-19 were more frequent than COPD with COVID-19 during the first outbreak, but the latter were associated with higher mortality and low eosinophil counts that warrant further analysis.
\end{abstract}

Keywords: COPD exacerbation, mortality, inhaled corticosteroids, hospitalization

\section{Introduction}

Exacerbations of chronic obstructive pulmonary disease (ECOPD) are a frequent cause of hospital admissions that seem to be modified by COVID-19. Although many studies have shown that various comorbidities, including COPD, are associated with high severity and mortality among the COVID-19 population, little is known about the characteristics of the SARS-CoV-2 infected COPD patients compared to patients that require admission for a severe COPD exacerbation. Moreover, the specific impact of SARS-CoV-2 infection in hospitalized COPD patients is not yet well established. In addition, the potential protective role of inhaled therapies for an adverse outcome of COVID-19 in COPD patients is yet to be explored. In the current study, we aimed to investigate the clinical characteristics and the role of therapies in consecutive patients with COPD with a respiratory-related hospital admission in Spain during the first outbreak wave of the COVID-19 pandemic and to evaluate the presence of COVID19 as a risk factor of mortality in this cohort. 
A

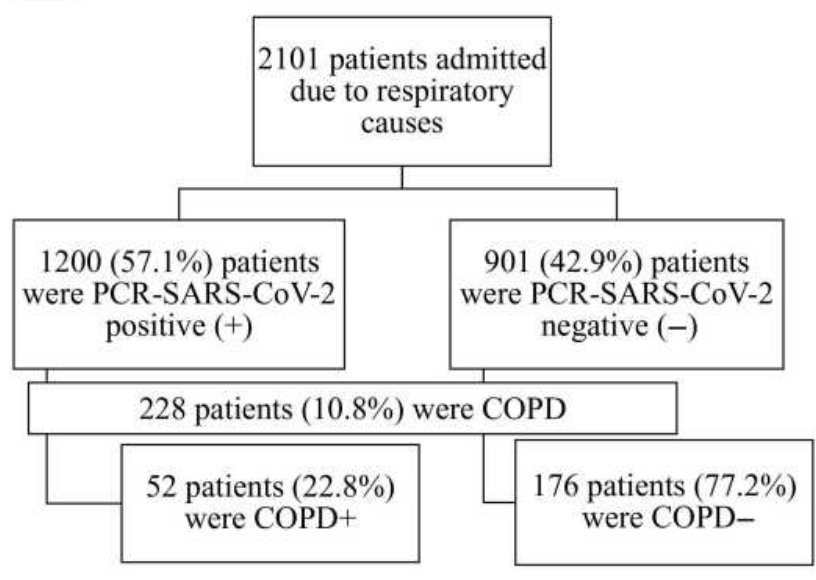

B

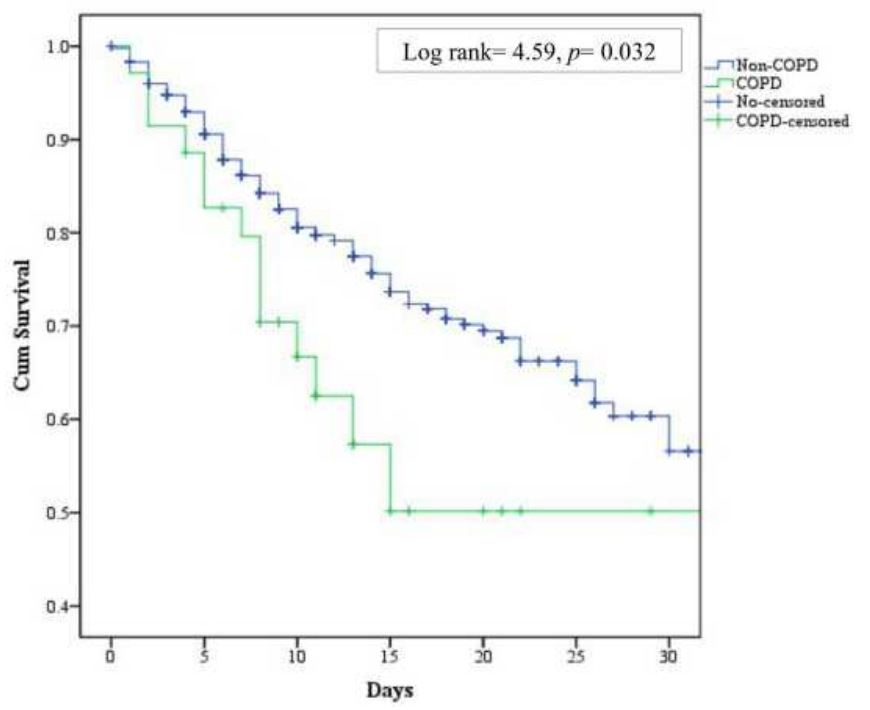

Figure I (A) Flow chart of the studied population. (B) Kaplan-Meier survival analysis of whole COVID-19 population in relation to the presence or absence of COPD as comorbidity.

\section{Patients and Methods}

We conducted a case-controlled study in four teaching hospitals between March 15 and April 30, 2020. All cases with COPD who were admitted to hospital due to any respiratory worsening were included. All the COPD patients enrolled in the current study had previous diagnosis of COPD according to GOLD criteria that was confirmed by postbronchodilator airflow limitation $\left(\mathrm{FEV}_{1} / \mathrm{FVC}<0.7\right)$ using forced spirometry testing. COVID-19 was identified using a polymerase chain reaction test for SARS-CoV-2 in nasopharynx samples. Baseline and episode-related clinical characteristics of the enrolled patients were analyzed. Bivariate and multivariate logistic analysis were used to evaluate the risk factors for inhospital mortality. Thirty-day in-hospital mortality was analyzed using Kaplan-Meier survival curve and log rank test among COVID-19 infected patients. The study was approved by the Research Board of Hospital Universitario Son Espases and the participating hospitals. Owing to the retrospective nature of the study informed consent was waived. We confirm that all patient data accessed complied with relevant data protection and privacy regulations, and that this study was conducted in accordance with the Declaration of Helsinki.

\section{Results}

Throughout the study duration, a total of 2101 patients were admitted for respiratory reasons in the participating hospitals, of which 1200 (57.1\%) patients were PCR-SARS-CoV
-2 positive. A total of $228(10.8 \%)$ were admitted due to COPD worsening, of whom 52 (22.8\%) tested positive for COVID-19 (Figure 1A). Baseline values revealed some differences between COPD cases positive for COVID-19 $(\mathrm{COPD}+)$ and COPD exacerbations without COVID-19 (COPD-). Both groups had similar mean age, comorbidities and smoking index. However, COPD+ were more frequently males $(92.3 \%$ vs $80.7 \%, p=0.048$; Table 1$)$. Baseline treatments were similar for both groups except for LAMA monotherapy more frequent in COPD+ $(13.5 \%$ vs $3.4 \%$, $p=0.028$; Table 1) and oxygen therapy more frequent in COPD- $(18.8 \%$ vs $5.8 \%, p=0.012$; Table 1$)$. Baseline postbronchodilator $\mathrm{FEV}_{1} \%$ predicted was significantly higher among COPD+ patients $(71 \%$; IQR $=52.75-82.75$ vs $46 \%$; $\mathrm{IQR}=31-60, p<0.001$; Table 1). C-reactive protein, D-dimer, lactate dehydrogenase and ferritin were significantly higher among COPD + patients $(p<0.05$ for all comparisons; Table $1)$. Blood analysis revealed lymphopenia and eosinopenia, more pronounced for COPD + cases ( $p<0.001$ for both comparisons; Table 1).

Clinical outcomes showed some differences. Notably, in-hospital mortality was significantly higher among COPD with COVID-19 patients vs COPD patients without COVID-19 (44.9\% vs $13.6 \%$ respectively; $p<0.001)$. There was no statistically significant difference regarding total days of hospitalization $(9.01 \pm 10.8$ vs $11.5 \pm 8.2$ days, $p=0.220)$ or admission to intensive care unit $(4.5 \%$ vs $5.8 \%, p=0.704$; Table 1) between COPD + and COPD-. 
Table I Baseline and Laboratory Characteristics of the Hospitalized COPD Population ( $=228,10.8 \%$ ) Classified According to Presence (COPD+) or Absence (COPD-) of COVID-19 Infection

\begin{tabular}{|c|c|c|c|}
\hline Variable & COPD- $(n=\mid 76 ; 77.2 \%)$ & COPD+ (n=52; 22.8\%) & Sig. ( $p$-value) \\
\hline Age; mean \pm SD & $71.98 \pm 10.96$ & $72.96 \pm 10.75$ & 0.568 \\
\hline Male/female; (n, \%) & $142(80.7) / 34(19.3)$ & $48(92.3) / 4(7.7)$ & $0.048^{*}$ \\
\hline $\begin{array}{l}\text { Smoking index (pack-years); } \\
\text { mean } \pm S D\end{array}$ & $55.37 \pm 26.03$ & $60.29 \pm 32.56$ & 0.558 \\
\hline Co-morbidities; (n, \%) & $148(84.1)$ & $45(86.5)$ & 0.667 \\
\hline Days of hospitalization; mean \pm SD & $9.01 \pm 10.76$ & II. $.49 \pm 8.24$ & 0.220 \\
\hline ICU admission; (n, \%) & $8(4.5)$ & $3(5.8)$ & 0.704 \\
\hline \multicolumn{4}{|l|}{ Medications; (n, \%) } \\
\hline LAMA & $6(3.4)$ & $7(13.5)$ & $0.028^{*}$ \\
\hline LAMA/LABA & $18(10.2)$ & $6(11.5)$ & 0.158 \\
\hline LABA/ICS & $9(5.1)$ & $5(9.6)$ & 0.193 \\
\hline Triple therapy & $42(23.9)$ & $6(11.5)$ & 0.110 \\
\hline Roflumilast & $6(3.4)$ & $0(0)$ & 0.195 \\
\hline Baseline oxygen therapy & $33(18.8)$ & $3(5.8)$ & $0.012^{*}$ \\
\hline Baseline NIV & $14(8)$ & $0(0)$ & 0.113 \\
\hline \multicolumn{4}{|l|}{ Baseline spirometry: } \\
\hline $\mathrm{FEV}, \%$ predicted & $46(31-60)$ & 71 (52.75-82.75) & $<0.00 I^{*}$ \\
\hline $\mathrm{FEV}_{\mathrm{I}}(\mathrm{mL})$ & $1170(910-1650)$ & $1745(922.5-2300)$ & $0.004^{*}$ \\
\hline $\mathrm{FEV}_{1} / \mathrm{FVC}$ & $44(36-58)$ & $60(43.5-67)$ & $0.028^{*}$ \\
\hline \multicolumn{4}{|l|}{ Laboratory data: } \\
\hline WBC (cells/uL) & $9830(7432.5-13425)$ & $7460(5660-10200)$ & $<0.00 I^{*}$ \\
\hline Lymphocytes (cells/uL) & $1250(822.5-1895.0)$ & $830(630-1200)$ & $<0.00 I^{*}$ \\
\hline Neutrophils (cells/uL) & $7780(53|2.5-1| 402.5)$ & $5800(3875-8085)$ & $0.007^{*}$ \\
\hline Eosinophils (cells/uL) & $80(30.0-177.5)$ & $20(0.0-70.0)$ & $<0.00 I^{*}$ \\
\hline LDH (U/L) & $193(\mid 55.75-287.0)$ & $328(267.25-475.75)$ & $<0.00 I^{*}$ \\
\hline Ferritin $(\mathrm{ng} / \mathrm{mL})$ & $191(92.0-646.5)$ & $776(340.5-1729.0)$ & $0.003^{*}$ \\
\hline D-dimer (ng/mL) & $406(199-1026)$ & $785(397.25-2354.25)$ & $0.021 *$ \\
\hline CRP (mg/L) & $4.42(0.45-22.69)$ & $28.84(10.97-69.5)$ & $<0.00 I^{*}$ \\
\hline \multicolumn{4}{|l|}{ Advanced treatment for COVID-19 } \\
\hline NIV; (n, \%) & $22(12.5)$ & $2(3.8)$ & $0.02 *$ \\
\hline MV; (n, \%) & $3(1.7)$ & $2(3.8)$ & 0.497 \\
\hline ECMO; (n, \%) & I (0.6) & $0(0)$ & 0.628 \\
\hline
\end{tabular}

Notes: Data are presented as median (interquartile range) unless otherwise stated. Statistics: $\chi^{2}$ test, Mann-Whitney and Student's $t$-tests were used as appropriate. *Significant $p$-value $<0.05$

Abbreviations: COPD-, COPD with negative PCR-SARS-CoV-2; COPD+, COPD with positive PCR-SARS-CoV-2; SD, standard deviation; n, number; ICU, intensive care unit; LAMA, long-acting muscarinic antagonist; LABA, long-acting beta 2 agonist; ICS, inhaled corticosteroid; NIV, noninvasive ventilation; FEV , forced expiratory volume in first second; FVC, forced vital capacity; mL, milliliter; WBC, white blood count; LDH, Lactic acid dehydrogenase; CRP, C-reactive protein; MV, mechanical ventilation; ECMO, extracorporeal membrane oxygenation.

When only COVID-19 patients were assessed, KaplanMeier survival analysis showed that COPD + patients had worse survival compared to those without COPD (50\% vs $60 \%$ respectively, $p=0.032$; Figure $1 \mathrm{~B}$ ).

Moreover, patients with COPD were at 2.8-fold higher risk of in-hospital mortality in COVID-19 population
(95\% $\mathrm{CI}=1.5-5.3, p=0.002)$ after correction for age, gender and other comorbidities despite being less likely to acquire COVID-19 disease (COPD+: 52/228 (22.8\%) vs nonCOPD with COVID-19: 1148/1873 (61.3\%); odds ratio $(\mathrm{OR})=0.19,95 \% \mathrm{CI}=0.14-0.26, p<0.001)$. It is noteworthy that treatment with inhaled corticosteroids (ICS) showed 
Table 2 Multivariate Logistic Analysis of the Predictors of Mortality Among Whole COPD Population

\begin{tabular}{|l|c|c|c|c|}
\hline & \multirow{2}{*}{ OR } & \multicolumn{2}{|c|}{$\mathbf{9 5 \% C I}$ for OR } & \multirow{2}{*}{$\begin{array}{c}\text { Sig. } \\
\text { (p-value) }\end{array}$} \\
\cline { 3 - 4 } & & Lower & Upper & \\
\hline Age & 1.89 & 0.86 & 4.19 & 0.116 \\
\hline Male gender & 3.18 & 0.35 & 28.95 & 0.304 \\
\hline $\begin{array}{l}\text { Comorbidities other than } \\
\text { respiratory }\end{array}$ & 1.23 & 0.18 & 8.53 & 0.835 \\
\hline COVID-19 infection & 4.99 & 1.30 & 19.17 & $0.019 *$ \\
\hline D-dimer & 1.27 & 0.81 & 1.97 & 0.300 \\
\hline CRP & 1.14 & 0.74 & 1.75 & 0.548 \\
\hline Eosinopenia & 2.11 & 1.08 & 4.16 & $0.030^{*}$ \\
\hline WBC & 1.12 & 0.66 & 1.90 & 0.673 \\
\hline Lymphopenia & 1.52 & 0.87 & 2.65 & 0.141 \\
\hline Intercept & 0.002 & & & $0.005 *$ \\
\hline
\end{tabular}

Note: *Significant $p$-value $<0.05$.

Abbreviations: $\mathrm{OR}$, odds ratio; $\mathrm{Cl}$, confidence interval.

a nonstatistically significant effect on mortality $(\mathrm{OR}=0.75$, 95\%CI $=0.24-2.33, \quad p=0.619)$ or acquiring COVID-19 among COPD patients $(\mathrm{OR}=0.48,95 \% \mathrm{CI}=0.18-1.28$, $p=0.141$ ).

Further, we found in multivariate logistic regression for mortality that COVID-19 and eosinopenia were the main determinants of in-hospital mortality after correction for age, gender, comorbidities and laboratory tests of interest $(\mathrm{OR}=4.99,95 \% \mathrm{CI}=1.3-19.17, p=0.019$ and $\mathrm{OR}=2.11$, $95 \% \mathrm{CI}=1.08-4.16, \quad p=0.03$ respectively; Table 2) in COPD patients.

\section{Discussion}

As shown in the current analysis, COPD patients infected with COVID-19 had higher mortality than COPD patients admitted for other cause of exacerbations. Interestingly, despite the higher mortality they showed less severe disease than COPD-, with milder airflow limitation, less intensive treatment for COPD and similar comorbidities. The reason for the increased risk of death is unclear but seems directly attributed to SARS-CoV-2 infection and their complications. Higher expression of angiotensinconverting enzyme 2 (ACE-2) receptor in the bronchial epithelium of COPD and smokers that facilitates the binding of SARS-CoV-2 to cells leading to infection ${ }^{1}$ could be an explanation of the severity of COVID-19 disease among COPD patients irrespective of the severity of underlying disease. A limited access to more advanced treatments such as noninvasive ventilation or ICU admission was not observed in our series. Gómez-Antúnez et al similarly found that neither noninvasive ventilation, highflow nasal cannula or invasive mechanical ventilation were associated with better survival among COPD infected with COVID-19. ${ }^{2}$

In line with our finding, a meta-analysis showed that COPD patients are at high risk for more severe COVID-19 disease and higher mortality compared to non-COPD patients. ${ }^{3}$ However, to our knowledge, the majority of the studies compared COPD and non-COPD patients hospitalized for COVID-19 rather than COPD admitted due to other causes. On the contrary, other reports did not list COPD as a comorbidity associated to mortality in their COVID-19 series. ${ }^{4,5}$

In addition, in the current analysis we found that COPD patients with more severe disease had less chance of acquiring SARS-CoV-2 infection which could be due to less active daily life, feeling compelled to self-isolat e because of fear of dying from COVID-19, more adherence to medications and satisfaction with medical telephone visits. ${ }^{6,7}$

Alternatively, we showed a lower prevalence of COVID-19 among COPD population. This finding is in accordance with Gómez-Antúnez et $\mathrm{al}^{2}$ who reported low prevalence of COPD among their analyzed 10,420 patients (7.16\%). Guan et al in China found that COPD constituted $1.3 \%$ of COVID-19 cases, ${ }^{8}$ while Cummings et al in New York City reported that COPD and interstitial lung diseases constituted $9 \%$ of their COVID-19 cases. $^{9}$ Alqahtani et $\mathrm{al}^{3}$ in their systematic review and metaanalysis found that $2 \%$ only of COVID- 19 patients were COPD. Interestingly, previous reports showed that neither MERS-CoV nor SARS-CoV-1 were associated with COPD exacerbation in contrast to other coronaviruses such as OCA3 and 229E. ${ }^{10}$ The exact cause is still unclear, but the use of inhaled steroids, beta-agonists or anticholinergics ${ }^{11}$ could be implicated through inhibition of the expression of coronavirus receptors, reduction of endosomal activity ${ }^{11}$ and modulation of the airway inflammatory response to coronavirus infection. ${ }^{12}$

Interestingly, ICS in the current analysis did not have a statistically significant protective effect against the development of COVID-19 among the COPD population or mortality in the bivariate or multivariate regression analysis. Despite that ICS use has a proven protective 
effect against exacerbations among frequent-exacerbator COPD patients, to date, there is no conclusive data supporting that ICS use is associated with reducing or increasing the risk of COVID-19 among COPD population. Schultze et al found that ICS did not provide a protection against severe COVID-19 infection in COPD patients but could be associated with overall increased risk of mortality. ${ }^{13}$ Choi et al, in another epidemiological study performed in Korea, found that ICS users had higher in-hospital mortality rates, but this association was not significant when adjusted for various confounding factors. ${ }^{14}$ On the contrary, a recent study showed that ICS and biological therapy in asthmatics may have a protective effect against the development of severe COVID-19. ${ }^{15}$

Lastly, COVID-19 and eosinopenia were the main determinants of in-hospital mortality in multivariate logistic analysis. Yang et al found that high blood eosinophils were associated with significant lower in-hospital mortality among critically ill patients admitted to hospital due to severe ECOPD. ${ }^{16}$ This could be explained based on a good response to systemic corticosteroids given in the management of ECOPD, especially if eosinophilic COPD phenotype. Furthermore, it has been previously reported that low eosinophils in peripheral blood is associated with potentially pathogenic bacterial infection ${ }^{17}$ and worse outcomes of ECOPD. Yan et al also found in 109 COVID-19 patients that progressive decline of eosinophilic count is linked to tissue damage and mortality. ${ }^{18}$

\section{Study Limitations}

The current study had some limitations. Firstly, we did not analyze the cause of COPD of the studied population; however, the main cause of COPD is smoking while a percentage is still caused by biomass population. Secondly, we did not investigate the prehospital use of systemic corticosteroids as risk factor of COVID-19 mortality among our COPD population. Choi et $\mathrm{al}^{14}$ and Williamson et $\mathrm{al}^{19}$ found that the use of systemic corticosteroids for COPD and asthma in the year prior to inclusion in the study was associated with significant increased risk of COVID-19 related mortality. Lastly, we could not compare the rate of exacerbation with those in preceding years; however, our aim was to compare them with COVID-19 in COPD patients.

\section{Conclusions}

Hospitalizations for ECOPD without COVID-19 were more frequent than COPD with COVID-19 during the first pandemic wave, but the latter were associated with higher mortality. The association of low eosinophil counts with higher mortality in the COPD with COVID-19 warrants further analysis. We found no evidence to support the role of ICS as protective factor for mortality due to SARSCoV-2 infection among COPD patients.

\section{Funding}

The study was partially funded by an unrestricted grant from GlaxoSmithKline (GSK) without any influence on the analysis and results of the current study.

\section{Disclosure}

Prof. Dr Borja G Cosio report grants, personal fees, nonfinancial support from GSK, AstraZeneca, Chiesi, Boehringer Ingelheim, Menarini, personal fees, nonfinancial support from Sanofi, Novartis, outside the submitted work; Dr Nuria Toledo-Pons report personal fees from AstraZeneca, GSK, outside the submitted work; Dr Jose Luis Lopez-Campos report personal fees, nonfinancial support from AstraZeneca, grants from Boehringer Ingelheim, Chiesi, CSL Behring, grants from Esteve, Ferrer, GebroPharma, GlaxoSmithKline, Grifols, Menarini, Novartis, Rovi, Teva, outside the submitted work; Dr Juan Jose Soler-Cataluna report personal fees from AstraZeneca, personal fees, nonfinancial support from Boehringer Ingelheim, personal fees from Bial, personal fees from Chiesi, grants, personal fees from GlaxoSmithKline, nonfinancial support from Esteve, Novartis, Rovi, Ferrer, Teva, outside the submitted work. The authors report no other conflicts of interest in this work.

\section{References}

1. Leung JM, Yang CX, Tam A, et al. ACE-2 expression in the small airway epithelia of smokers and COPD patients: implications for COVID-19. Eur Respir J. 2020;55(5):2000688. doi:10.1183/ 13993003.00688-2020

2. Gómez Antúnez M, Muiño Míguez A, Bendala Estrada AD, et al. Clinical characteristics and prognosis of COPD patients hospitalized with SARS-CoV-2. Int $J$ Chron Obstruct Pulmon Dis. 2020;15:3433-3445. doi:10.2147/copd.S276692

3. Alqahtani JS, Oyelade T, Aldhahir AM, et al. Prevalence, severity and mortality associated with COPD and smoking in patients with COVID-19: a rapid systematic review and meta-analysis. PLoS One. 2020;15(5):e0233147. doi:10.1371/journal.pone.0233147

4. Onder G, Rezza G, Brusaferro S. Case-fatality rate and characteristics of patients dying in relation to COVID-19 in Italy. JAMA. 2020;323 (18):1775-1776. doi:10.1001/jama.2020.4683

5. Yang X, Yu Y, Xu J, et al. Clinical course and outcomes of critically ill patients with SARS-CoV-2 pneumonia in Wuhan, China: a single-centered, retrospective, observational study. Lancet Respir Med. 2020;8(5):475-481. doi:10.1016/s2213-2600(20)30079-5 
6. Pleguezuelos E, Del Carmen A, Moreno E, et al. The experience of COPD patients in lockdown due to the COVID-19 pandemic. Int J Chron Obstruct Pulmon Dis. 2020;15:2621-2627. doi:10.2147/copd.S268421

7. Mousing CA, Sørensen D. Living with the risk of being infected: COPD patients' experiences during the coronavirus pandemic. J Clin Nurs. 2021;30(11-12):1719-1729. doi:10.1111/jocn.15727

8. Guan WJ, Liang WH, Zhao Y, et al. Comorbidity and its impact on 1590 patients with COVID-19 in China: a nationwide analysis. Eur Respir J. 2020;55(5):2000547. doi:10.1183/13993003.00547-2020

9. Cummings MJ, Baldwin MR, Abrams D, et al. Epidemiology, clinical course, and outcomes of critically ill adults with COVID-19 in New York City: a prospective cohort study. Lancet. 2020;395 (10239):1763-1770. doi:10.1016/s0140-6736(20)31189-2

10. Kurai D, Saraya T, Ishii H, Takizawa H. Virus-induced exacerbations in asthma and COPD. Front Microbiol. 2013;4:293. doi:10.3389/ fmicb.2013.00293

11. Yamaya $M$, Nishimura H, Deng $X$, et al. Inhibitory effects of glycopyrronium, formoterol, and budesonide on coronavirus HCoV-229E replication and cytokine production by primary cultures of human nasal and tracheal epithelial cells. Respir Investig. 2020;58 (3):155-168. doi:10.1016/j.resinv.2019.12.005

12. Bucher H, Duechs MJ, Tilp C, Jung B, Erb KJ. Tiotropium attenuates virus-induced pulmonary inflammation in cigarette smoke-exposed mice. J Pharmacol Exp Ther. 2016;357(3):606-618. doi:10.1124/ jpet.116.232009
13. Schultze A, Walker AJ, MacKenna B, et al. Risk of COVID-19related death among patients with chronic obstructive pulmonary disease or asthma prescribed inhaled corticosteroids: an observational cohort study using the OpenSAFELY platform. Lancet Respir Med. 2020;8(11):1106-1120. doi:10.1016/S2213-2600(20)30415-X

14. Choi JC, Jung SY, Yoon UA, et al. Inhaled corticosteroids and COVID-19 risk and mortality: a Nationwide Cohort Study. J Clin Med. 2020;9(11):3406. doi:10.3390/jcm9113406

15. Izquierdo JL, Almonacid C, Gonzalez Y, et al. The impact of COVID-19 on patients with asthma. Eur Respir J. 2021;57 (3):2003142. doi:10.1183/13993003.03142-2020

16. Yang J, Yang J. Association between blood eosinophils and mortality in critically ill patients with acute exacerbation of chronic obstructive pulmonary disease: a Retrospective Cohort Study. Int J Chron Obstruct Pulmon Dis. 2021;16:281-288. doi:10.2147/copd.S289920

17. Choi J, Oh JY, Lee YS, et al. The association between blood eosinophil percent and bacterial infection in acute exacerbation of chronic obstructive pulmonary disease. Int J Chron Obstruct Pulmon Dis. 2019;14:953-959. doi:10.2147/copd.S197361

18. Yan B, Yang J, Xie Y, Tang X. Relationship between blood eosinophil levels and COVID-19 mortality. World Allergy Organ J. 2021;14 (3):100521. doi:10.1016/j.waojou.2021.100521

19. Williamson EJ, Walker AJ, Bhaskaran K, et al. Factors associated with COVID-19-related death using OpenSAFELY. Nature. 2020;584 (7821):430-436. doi:10.1038/s41586-020-2521-4

\section{Publish your work in this journal}

The International Journal of COPD is an international, peer-reviewed journal of therapeutics and pharmacology focusing on concise rapid reporting of clinical studies and reviews in COPD. Special focus is given to the pathophysiological processes underlying the disease, intervention programs, patient focused education, and self management protocols. This journal is indexed on PubMed Central, MedLine and CAS. The manuscript management system is completely online and includes a very quick and fair peer-review system, which is all easy to use. Visit http://www.dovepress.com/testimonials.php to read real quotes from published authors. 